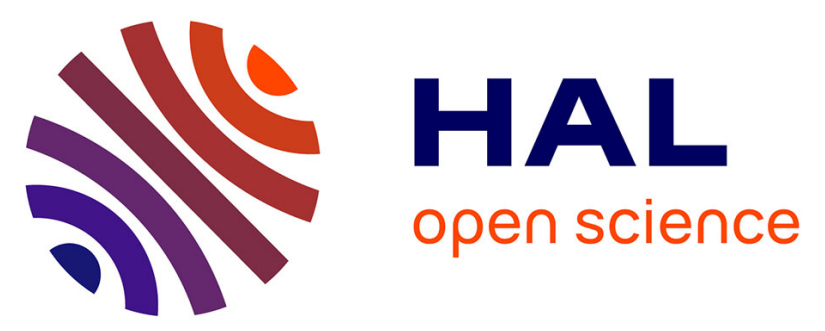

\title{
Modeling the Voltage Drop Across the Cathode Sheath in HPS
}

\author{
José Luis Tapia Fabela, Joel Osbaldo Pacheco-Sotelo, Marquidia Pacheco \\ Pacheco, Jorge Samuel Benítez-Read, Régulo López-Callejas, Georges Zissis, \\ Sounil Bhosle
}

\section{To cite this version:}

José Luis Tapia Fabela, Joel Osbaldo Pacheco-Sotelo, Marquidia Pacheco Pacheco, Jorge Samuel Benítez-Read, Régulo López-Callejas, et al.. Modeling the Voltage Drop Across the Cathode Sheath in HPS. IEEE Transactions on Plasma Science, 2007, 35 (4), pp.1104-1110. 10.1109/TPS.2007.902125 . hal-00188969

\section{HAL Id: hal-00188969 \\ https://hal.science/hal-00188969}

Submitted on 19 Nov 2007

HAL is a multi-disciplinary open access archive for the deposit and dissemination of scientific research documents, whether they are published or not. The documents may come from teaching and research institutions in France or abroad, or from public or private research centers.
L'archive ouverte pluridisciplinaire HAL, est destinée au dépôt et à la diffusion de documents scientifiques de niveau recherche, publiés ou non, émanant des établissements d'enseignement et de recherche français ou étrangers, des laboratoires publics ou privés. 


\title{
Modeling the Voltage Drop Across the Cathode Sheath in HPS
}

\author{
José Luis Tapia Fabela, Joel Osbaldo Pacheco-Sotelo, Marquidia Pacheco Pacheco, Jorge Samuel Benítez-Read, \\ Régulo López-Callejas, Georges Zissis, Senior Member, IEEE, and Sounil Bhosle, Member, IEEE
}

\begin{abstract}
An electrical cathode model (ECM) of a highpressure sodium (HPS) lamp based on physical laws has been developed. The proposed ECM calculates the instantaneous voltage drop in a cathode sheath and the temperature distribution inside the cathode using as input parameter the cathode geometry and the positive column current. The model is based on the electrode heat transport equation, which is solved using the finite-element method. So, since it stems from the physics describing the cathode behavior, it is found that the ECM predicts in a satisfactory way the cathode voltage drop over a wide range of work conditions. The obtained results were compared with those reported in the current literature. It can be concluded that the ECM is a useful tool in understanding the interaction between the positive column and the cathode in order to improve, for instance, HPS lamp ballast designs, as measuring the potential drop across the cathode sheath using a commercial lamp is particularly difficult. The model takes into account the temperature dependence of the thermal conductivity, the electrical cathode resistivity, and the total emissivity.
\end{abstract}

Index Terms-Cathode temperature distribution, electrical cathode model (ECM), finite-element method, high-pressure sodium (HPS) lamps.

\section{INTRODUCTION}

$\mathbf{T}$ HE ELECTRODES of a gas discharge lamp act as an interface between the positive column and the electronic circuit. An important fraction of the total lamp input power is lost by dissipation through the electrodes. Therefore, it is essential to understand the interaction between electrodes and positive column in order to improve performance by reducing the electrode losses.

Since high-pressure sodium (HPS) discharges normally work under an alternating current, each electrode acts as both anode and cathode during each period. From an electrical point of view, the voltage drop at the anode is negligible with respect

Manuscript received November 14, 2006; revised April 3, 2007. This work was supported in part by PCP-CONACyT under Contract 46959, by SEP-CONACyT under Contract 512.05P, and by DGEST, México, under Contract $402003082 \mathrm{MP}$.

J. L. T. Fabela, J. O. Pacheco-Sotelo, J. S. Benítez-Read, and R. LópezCallejas are with the Instituto Tecnológico de Toluca, 52140 Metepec, México, and also with the Instituto Nacional de Investigaciones Nucleares, 11801 México DF, México (e-mail: jps@ @uclear.inin.mx).

M. P. Pacheco is with the Instituto Nacional de Investigaciones Nucleares, 11801 México DF, México.

G. Zissis and S. Bhosle are with the Laboratoire Plasma et Conversion d'Energie, UMR-5213, Université Paul Sabatier, 31062 Toulouse, France.

Color versions of one or more of the figures in this paper are available online at http://ieeexplore.iee.org.

Digital Object Identifier 10.1109/TPS.2007.902125 to that at the cathode [1]. Therefore, by using only a cathode model, it is possible to obtain a reasonable representation of the electrical interaction between electrodes and positive column, with a considerable reduction of complexity.

The experimental study of the relationship between the cathode and positive column is not particularly easy because it necessitates a sophisticated experimental setup to take the measurements. Consequently, numerical modeling of the plasma-cathode interaction represents an option to carry out this study. In this paper, an electrical cathode model (ECM) is proposed to predict the voltage drop across the cathode sheath under different work conditions. Using the ECM, it is possible to study the cathode operation. The ECM is based on the equation of the electrode power at the front of the rod that was proposed by de Groot and Van Vliet [2]. This equation relates the temperature gradient at the front of the electrode (active surface) with the electrical power losses in the electrode.

The aim of this paper is to present a numerical cathode model for an HPS discharge that is able to predict the cathode voltage drop at different frequencies and supply current waveforms. The model was developed in Matlab language applying the finite-element method. Since this model is based on the physical equations that decree the cathode behavior, it is valid over a wide range of operation conditions. The ECM user only needs to enter the amplitude, frequency, and waveform of the positive column current, and for a given cathode geometry, the model predicts the instantaneous voltage drop across the cathode sheath. Besides, the ECM enables the determination of the temperature distribution inside the cathode. This is of great interest because the lifetime of the HPS lamps is strongly related to it [3].

In order to determine the electrical losses at the cathode, it is necessary to calculate the temperature gradient on the active surface (Section III-A) and the temperature distribution through the cathode (Section III-B). The temperature distribution in the electrode at a given time can be calculated by means of the electrode heat transport equation (Section III-B). Using the cathode temperature distribution, it has been possible to obtain the temperature gradient in the active surface and, consequently, the electrode power losses (Section IV-C).

\section{CAthode Geometry}

The cathode of an HPS discharge lamp is usually manufactured from a refractory material having a high melting point that is meant to support high temperatures of operation. The cathode geometry of an HPS lamp discharge is shown in Fig. 1. 


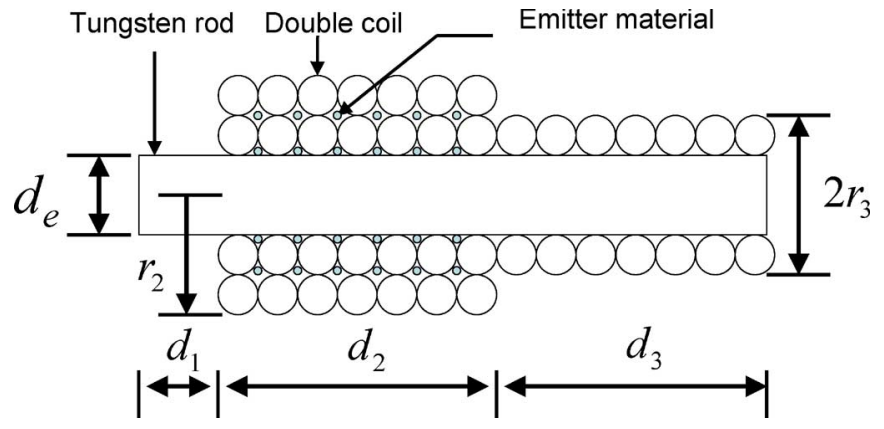

Fig. 1. Longitudinal cross section of a typical electrode used in HPS lamps.

With an aim to increase the emission surface, the HPS lamp cathodes are composed of a tungsten rod wrapped in one or two coils of the same material. A mixture that is composed of oxides (generally, $\mathrm{BaO}$ or $\mathrm{CaO}$ ) and carbonates (emitter materials such as $\mathrm{BaCO}_{3}$ or $\mathrm{CaCO}_{3}$ ) is deposited between the coils in order to increase the electron emission. The reaction of the oxides with the tungsten, i.e., $6 \mathrm{BaO}+\mathrm{W} \rightarrow \mathrm{Ba}_{3} \mathrm{WO}_{6}+$ $3 \mathrm{Ba}$ [2], generates the required free barium for the formation of a monolayer that is capable of reducing the electrode work function in such a way that the operation of the lamp is improved.

\section{Cathode Modeling}

After the definition of Groot and van Vlient [2], the electrical losses $P_{e l}$ at the front of the cathode $(y=0)$ are defined by

$$
P_{e l}=\frac{1}{4} \pi\left(d_{e}\right)^{3 / 2} k\left(\frac{d T}{d y}\right)_{y=0}
$$

where $d_{e}$ symbolizes diameter of the rode-type electrode, $k$ is the tungsten thermal conductivity, $T$ is the electrode temperature, and $y=z\left(d_{e}^{-1 / 2}\right)$ is the reduced axial coordinate, with $z$ equal to the axial coordinate. From (1), it is possible to appreciate that the voltage drop at the front of the cathode is related to the temperature gradient at its active surface. So, in order to calculate the electric losses at the cathode sheath, it is necessary to obtain the temperature distribution through the cathode, based on the cathode boundary conditions. Once the cathode temperature distribution is known, then it is possible to specify the temperature gradient at the active surface.

\section{A. Temperature Calculation at the Cathode Active Surface}

To remove an electron from a metallic surface, it is necessary that the electron absorbs enough energy from an external source to escape from the electric potential barrier that originally confined it. This energy is called the work function. The Fermi level is the top of all possible electron energy levels at absolute zero temperature. If a metal is warmed up, its electrons exceed the Fermi level, and the energy is distributed according to the Fermi-Dirac statistic. With a higher temperature of the metal, the number of electrons with sufficient energy to scale the potential barrier and leave the metal is increased.

The process briefly described here is called thermionic emission. In the cathode of an HPS discharge, the thermionic emission is enhanced by the electric field applied and by the presence of an activator, which lowers the work function of the electrode surface.

It has been assumed in this paper that the local discharge current density in the cathode active surface $j$ is $j=j_{i}+j_{e}$, where $j_{i}$ represents the ionic current density and $j_{e}$ is the electron current density composed by the thermoionic emission $j_{e}^{t h}$ [described by the equation of Richardson-Dushman (4)] corrected by the electric field and the secondary electron emission $j_{e}^{\text {sec }}$ related to the $\gamma$-Townsend process $j_{e}=j_{e}^{t h}+j_{e}^{\text {sec }}$. According to [4], the emission of secondary electrons due to the bombardment of sodium ions over a tungsten cathode is equal to $1 \%$ of the ions that reach the cathode. Using the $\beta$-Waymouth coefficient, which relates the ionic $j_{i}$ and electronic $j_{e}$ currents at the cathode sheath of a HPS discharge [5], [6], we have

$$
\begin{aligned}
\beta=\frac{j_{i}}{j_{e}} & =\frac{j_{i}}{j_{e}^{t h}+j_{e}^{\mathrm{sec}}} \\
j_{e}^{\mathrm{sec}} & =\gamma j_{i} \\
j_{e}^{t h} & =A T^{2} \exp \left(\frac{e \varphi\left(E_{k}\right)}{k_{B} T}\right)
\end{aligned}
$$

where $A=\left(4 \pi e m_{e} k_{B}^{2}\right) / h^{3}=1.2 \times 10^{6} \mathrm{Am}^{-2} \mathrm{~K}^{-2}$ represents the Richardson constant [6]-[8], $e$ is the electron charge, $k_{B}$ is the Boltzmann constant, and $E_{k}$ corresponds to the electric field on the cathode sheath, which is related to the potential drop at the cathode sheath $V_{k}$ in the MacKeown equation [9] $E_{k}^{2} \approx\left(4 j_{i} / \varepsilon_{0}\right) \sqrt{m_{i} V_{k} / 2 e}$, where, in turn, $m_{i}$ represents the sodium ionic mass, $\varepsilon_{0}$ is equal to the vacuum permittivity, and

$$
\varphi\left(E_{k}\right)=\varphi_{0}-\Delta \varphi\left(E_{k}\right), \quad \Delta \varphi\left(E_{k}\right)=\sqrt{\frac{e E_{k}}{4 \pi \varepsilon_{0}}} .
$$

Here, $\varphi_{0}$ is the tungsten work function, and $\Delta \varphi$ symbolizes the Schottky correction for the tungsten work function.

In HID lamps, two modes of cathodic arc attachment have been observed mainly: 1) the diffuse mode and 2) the spot mode. The major difference between the diffuse and spot modes is the current density, which is low in the case of the diffuse mode and high in the spot mode and the area of the arc attachment. With the aim of calculate the temperature at the cathode active surface for an HPS discharge, it can be assumed that the mode of cathodic arc attachment is the diffuse mode [10]. When the cathode operates in diffuse mode, the plasma covers the active surface of the electrode and their sides. In this paper, only the active surface is considered in the electronic emission. The operation of the cathode in diffuse mode is favored by the presence of an electric field lower than $\left(E<10^{7} \mathrm{~V} / \mathrm{m}\right)$, a current density $\left(j<10^{8} \mathrm{~A} / \mathrm{m}^{2}\right)$, a weak cooling of the electrode and a low discharge pressure.

Taking into account the previous arguments and substituting (2) and (3) into (4), it is possible to derive the following equation, which relate the total density of current to the temperature of the active surface of the cathode $T_{\text {act }}$ :

$$
j=\left(\frac{1+\beta}{1-\gamma \beta}\right) A T_{\mathrm{act}}^{2} \exp \left(\frac{e \varphi\left(E_{k}\right)}{k_{B} T_{\mathrm{act}}}\right) .
$$


TABLE I

TUNGSTEN COEFFICIENTS

\begin{tabular}{|c|c|c|}
\hline Symbol & Value & Units \\
\hline$\rho$ & 19300 & {$\left[\mathrm{~kg} \mathrm{~m}^{-3}\right]$} \\
\hline$c$ & 133 & {$\left[\mathrm{~J} \mathrm{~kg}^{-1} \mathrm{~K}^{-1}\right]$} \\
\hline$k$ & $776 /\left(\mathrm{T}^{0.256}\right)$ & {$\left[\mathrm{W} \mathrm{m}^{-1} \mathrm{~K}^{-1}\right]$} \\
\hline$\rho_{0}$ & $5.28 \times 10^{-8}$ & {$[\mathrm{~W} \mathrm{~m}]$} \\
\hline$\alpha$ & $6.76 \times 10^{-3}$ & {$\left[\mathrm{~K}^{-1}\right]$} \\
\hline
\end{tabular}

By solving the previous equation, it is possible to calculate the temperature in the cathode active surface. According to Waymouth [5], the value of $\beta$ was considered as the $20 \%$ of the electrons current density. Using (6), we have confirmed that, changing $\beta$ by $100 \%$, the temperature at the active surface changes only $5 \%$.

\section{B. Heat Transport Equation of the Cathode}

The temperature distribution inside the cathode body and at the surface may be found by means of solving the heat flux equation in the cathode body (7), with the prevailing boundary conditions (see Section III-C). The following equation describes the variation in the quantity of heat per unit of volume of the electrode [2], [6]:

$$
\rho c \frac{\partial T}{\partial t}=S+\nabla(k \nabla T)
$$

where $\rho$ symbolizes the mass density, $c$ is the specific heat capacity, $T$ is the electrode temperature, $t$ denotes the time dependent of the equation, and $k$ represents the thermal conductivity of the tungsten. The term $S$ from (7) represents the power that is supplied by the electric field to the electrode and is given by the Joule effect [6], i.e.,

$$
S=\rho_{e} j^{2}
$$

Here, $j$ represents the discharge current density, and $\rho_{e}$ is the electrical conductivity of the electrode. The heat produced in the electrode material by the discharge current causes the rise in the electrode temperature and consequently $\rho_{e}$ change; this change is given by the relation

$$
\rho_{e}(T)=\rho_{0}\left\{1+\alpha\left[T-T_{0}\right]\right\} .
$$

Now, the constants $\rho_{0}$ and $\alpha$ depend on the cathode material. The values for tungsten are shown in Table I. $T_{0}$ is the active surface temperature. The following condition for the total discharge current must be verified:

$$
2 \pi \int_{0}^{r_{0}} j r d r=I
$$

where $r_{0}=d_{e} / 2$ is the radius of the cathode, $r$ is the radial coordinate, and $I$ is the discharge current.

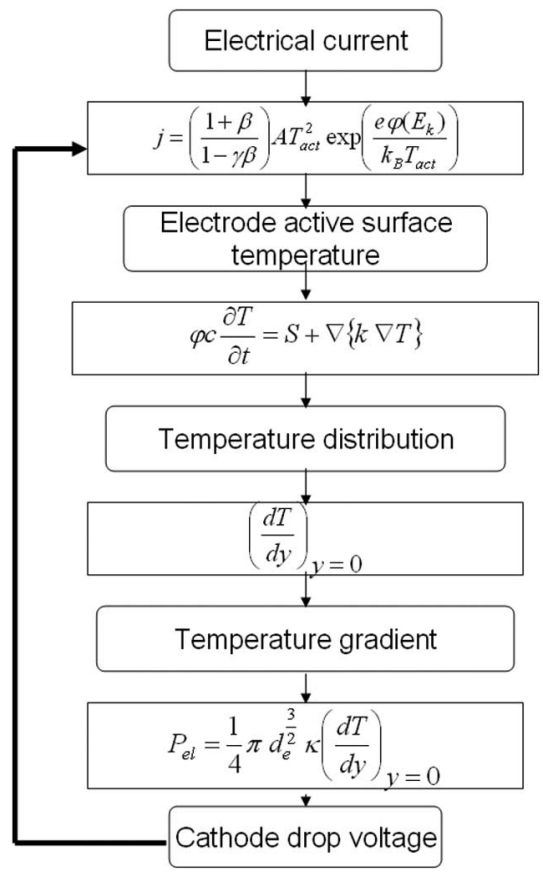

Fig. 2. Structured solution to compute the cathode voltage drop.

\section{Boundary Conditions}

The front (active surface) and end of the cathode were characterized by the Dirichlet boundary condition. The temperature at the end of the cathode was experimentally measured [6] and taken as $T_{\text {end }}=600 \mathrm{~K}$, and active surface temperature $T_{\text {act }}$ is obtained by solving (6). The cathode boundary conditions on the lateral borders can be classified as the Neumann condition; the physical meaning of this condition is a continuous energy flow (radiation, conduction, and convection) between the cathode and the adjacent medium. The equation that defines the boundary conditions is [11]

$$
k\left(T_{b}\right)\left(\frac{\partial T}{\partial \bar{n}}\right)_{b}=\bar{n}\left[\zeta\left(T_{b}-T_{\mathrm{amb}}\right)+\varepsilon_{w}\left(T_{b}\right) \sigma\left(T_{b}^{4}-T_{\mathrm{amb}}^{4}\right)\right]
$$

where $T_{b}$ represents the temperature on the cathode border, $T_{\mathrm{amb}}$ is the ambient temperature, $\zeta$ is the convection transport coefficient, $\varepsilon_{w}$ is the tungsten emissivity, and $\sigma$ symbolizes the Stefan Boltzmann constant. The term $(\partial T / \partial \bar{n})_{b}$ means the temperature derivative in the direction $\bar{n}$ normal to the cathode surface.

\section{RESUlt AND DiscusSiON}

The flowchart represented in Fig. 2 shows a summary of the procedure used to calculate the cathode voltage drop. In this chart, the input and output parameters are represented by rounded rectangles, so as to differentiate them from the processing steps.

As we can see, in order to obtain the temperature at the electrode active surface, it is necessary to know the initial cathode voltage drop and the discharge current. With the obtained temperature, it is possible to calculate the temperature 


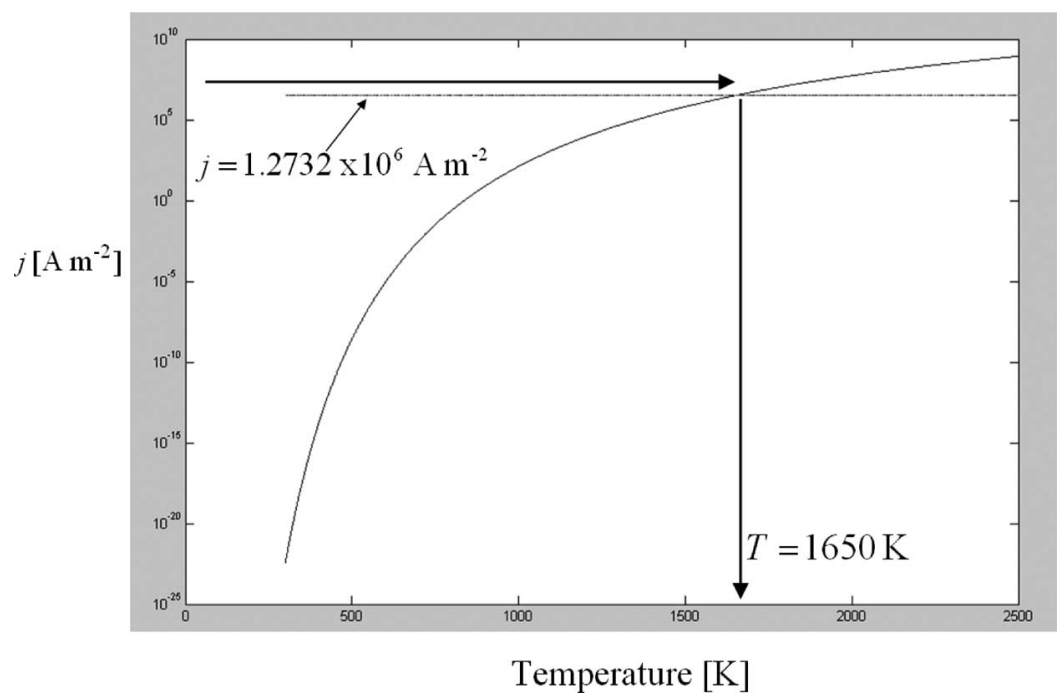

Fig. 3. Graphic solution for the temperature at the cathode active surface using a discharge current density of $j=1.2732 \times 10^{6} \mathrm{Am}^{-2}$.

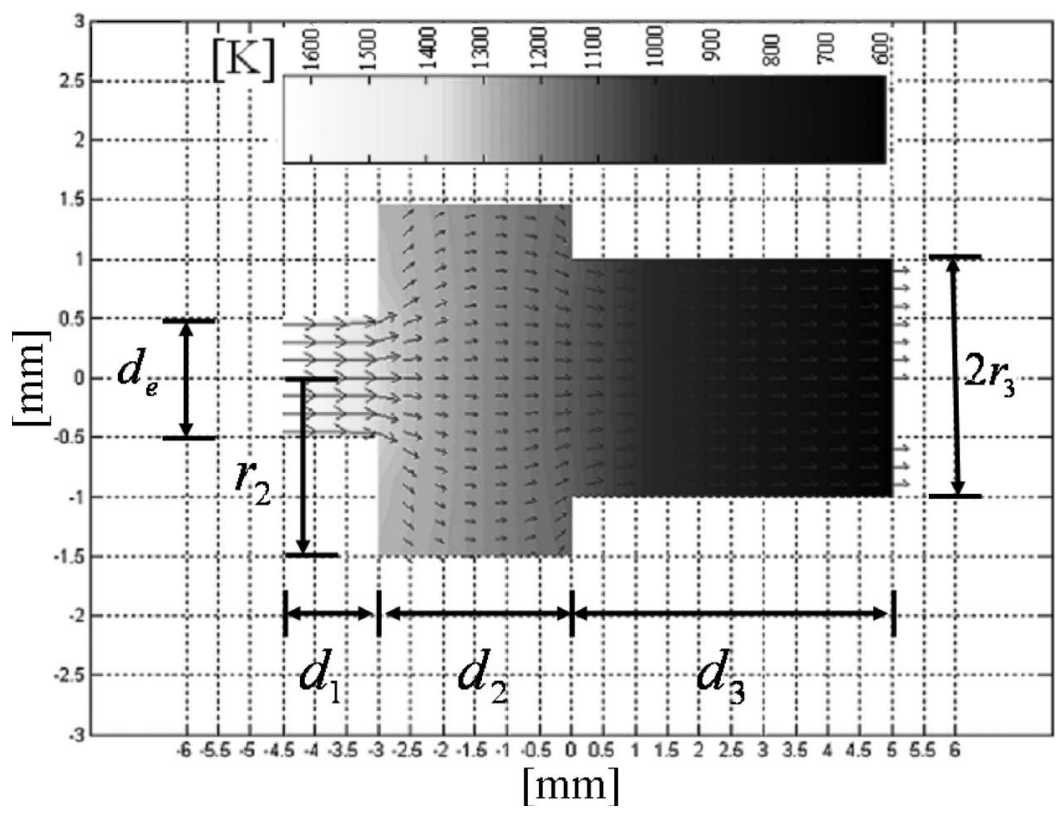

Fig. 4. Temperature distribution (gray scale) and heat flow (arrows) in an HPS discharge cathode.

distribution through the electrode, and following the next steps, a new cathode voltage drop can be obtained. The process is repeated until the program output converges.

Equation (7) was solved by the Matlab finite-element method [12]. The characteristics of the employed cathode were the following (see Fig. 1): $d_{e}=1 \mathrm{~mm}, r_{2}=1.5 \mathrm{~mm}, r_{3}=1.0 \mathrm{~mm}$, $d_{1}=1.5 \mathrm{~mm}, d_{2}=3 \mathrm{~mm}$, and $d_{3}=5 \mathrm{~mm}$. The resulting values are presented here.

\section{A. Temperature Calculation at the Active Surface of the Cathode}

This temperature is obtained by solving (6). The solution was obtained by means of an iterative process that changes the active surface temperature until converging with the discharge current density. In other words, the solution of (6) is a temperature that produces an electric current density equal to the discharge. The results for a discharge current density of $1.2732 \times 10^{6} \mathrm{~A} / \mathrm{m}^{2}$ in an HPS lamp $(400 \mathrm{~W})$ are shown in Fig. 3. The temperature obtained at the active surface reaches $1650 \mathrm{~K}$.

\section{B. Temperature Distribution Through the Cathode}

The temperature distribution through the cathode of an HPS discharge for an active surface temperature $T_{\text {act }}=1650 \mathrm{~K}$ is exhibited in Fig. 4, which corresponds to a 4-A discharge current. It can be observed that the temperature distribution has axial symmetry. Considering that the emissive layer consumption rate in diffuse mode is the same in all points, the cathode will work appropriately until the depletion of the emissive layer takes place. The temperature distribution inside the cathode is of great interest because the lifetime of the HPS lamps is strongly related to it [7]. 


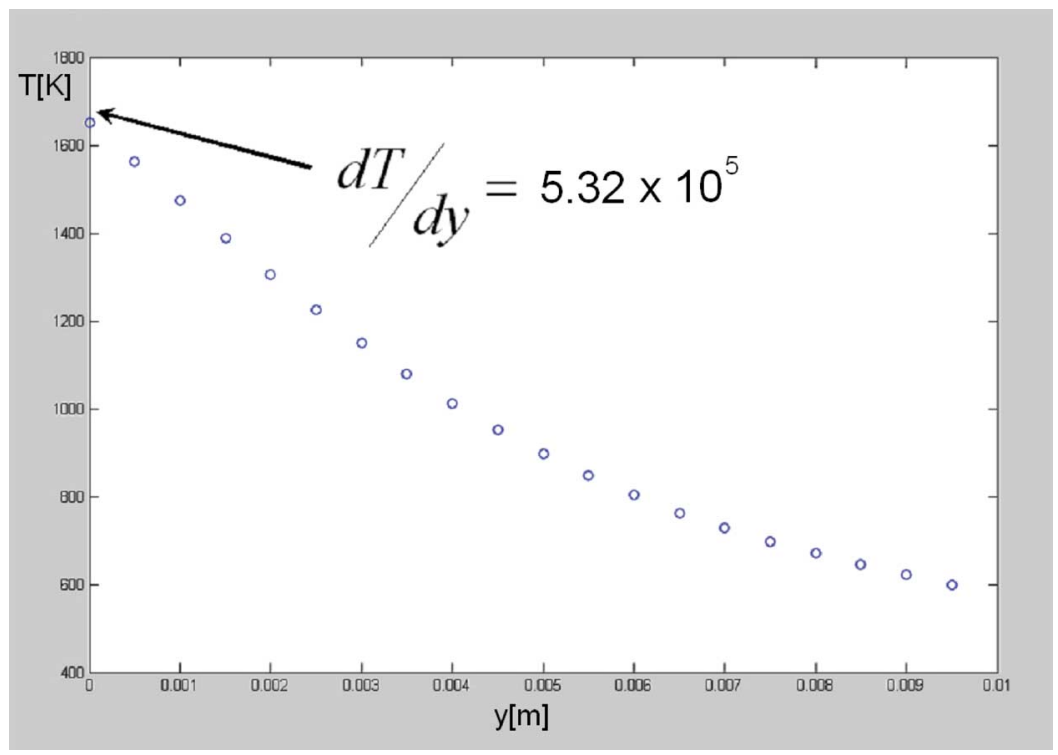

Fig. 5. Temperature gradient at the front of the electrode using a sinusoidal current of $4 \mathrm{~A}$.

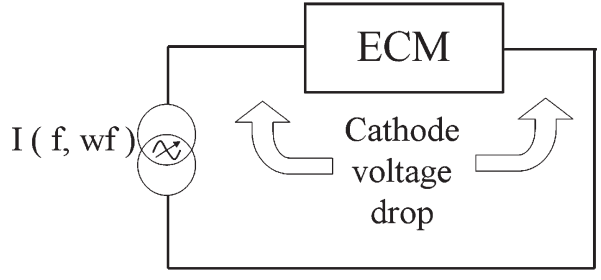

Fig. 6. Diagram of the proposed ECM.

\section{Temperature Gradient at the Rod Front}

By knowing the temperature distribution in the cathode, the temperature gradient at the front of the rod can be deduced. The temperature distribution profile through the cathode center is displayed in Fig. 5. At the front of the electrode, the temperature is $1650 \mathrm{~K}$; nevertheless, when we approached the back of the cathode, the temperature decreases until $600 \mathrm{~K}$. The temperature decrease is due to the cathode conduction [(7) and (11)] and radiation losses defined by (11). The temperature gradient at the front of the electrode is also shown in Fig. 5. The temperature profile was compared with references [6], [13], and [14], proving to be in close agreement.

\section{Cathode Voltage Drop for Different Frequencies}

By using the temperature gradient obtained in the previous section, the electrical power (1) can be established, and consequently, the cathode voltage drop can be determined. The procedure adopted in this paper for assessing the influence of the frequency and waveform of the discharge current supply in the cathode operation is summarized in Fig. 6. We apply a current source $I$ with variable frequency $f$ and waveform $w f$ to the ECM. The $X Y$ cathode $V-I$ characteristics of an HPS $(400 \mathrm{~W})$ discharge using a sinusoidal current at different frequencies are shown in Fig. 7. Notice that the hysteresis phenomenon appears mainly at low frequencies because the cathode temperature modulation is greater and an extra energy is necessary in each cycle to reach the work temperature.
According to Fig. 7, increasing the sinusoidal current frequency, the hysteresis at the electric cathode characteristics is reduced. This can be translated into a modulation decrease of the discharge impedance and better electronic control. To validate the model, some typical results obtained for tungsten cathodes in HPS discharges are reported in Table II.

The peak cathode voltage drop for an HPS lamp (400 W) is around $20 \mathrm{~V}$ when the discharge current is $4 \mathrm{~A}$ [5]. The differences appearing are probably due to the simplifying assumptions considered in the present model.

\section{CONCLUSiON}

An electrical model for the cathode of an HPS discharge intended for lamp ballast simulation has been developed in this paper. The model was based on the heat transfer equation for the electrode and implemented in Matlab using the finiteelement method. Since the model is built on the physical equations that define the cathode behavior over a wide range of operation conditions, the ECM is able to predict the electrical behavior of the cathode for different frequencies and supply current waveforms. The experimental study of the interaction between the cathode and positive column is a difficult task to carry out; because it necessitates a sophisticated experimental setup to make the measurements, consequently, the ECM model represents an excellent alternative. The ECM user only needs to supply the amplitude, frequency, and waveform of the positive column current, and for a given cathode geometry, the model predicts the instantaneous drop of voltage at the cathode sheath. Furthermore, the ECM enables to know the temperature distribution inside the cathode. This is of a great interest provided that the lifetime of HPS lamps is strongly related to it.

The obtained results using the model have been compared with the current literature, finding a good agreement, even at different work conditions. Thus, we concluded that the ECM is a useful tool in understanding the interaction between the positive column and the cathode in order to improve ballast design. 

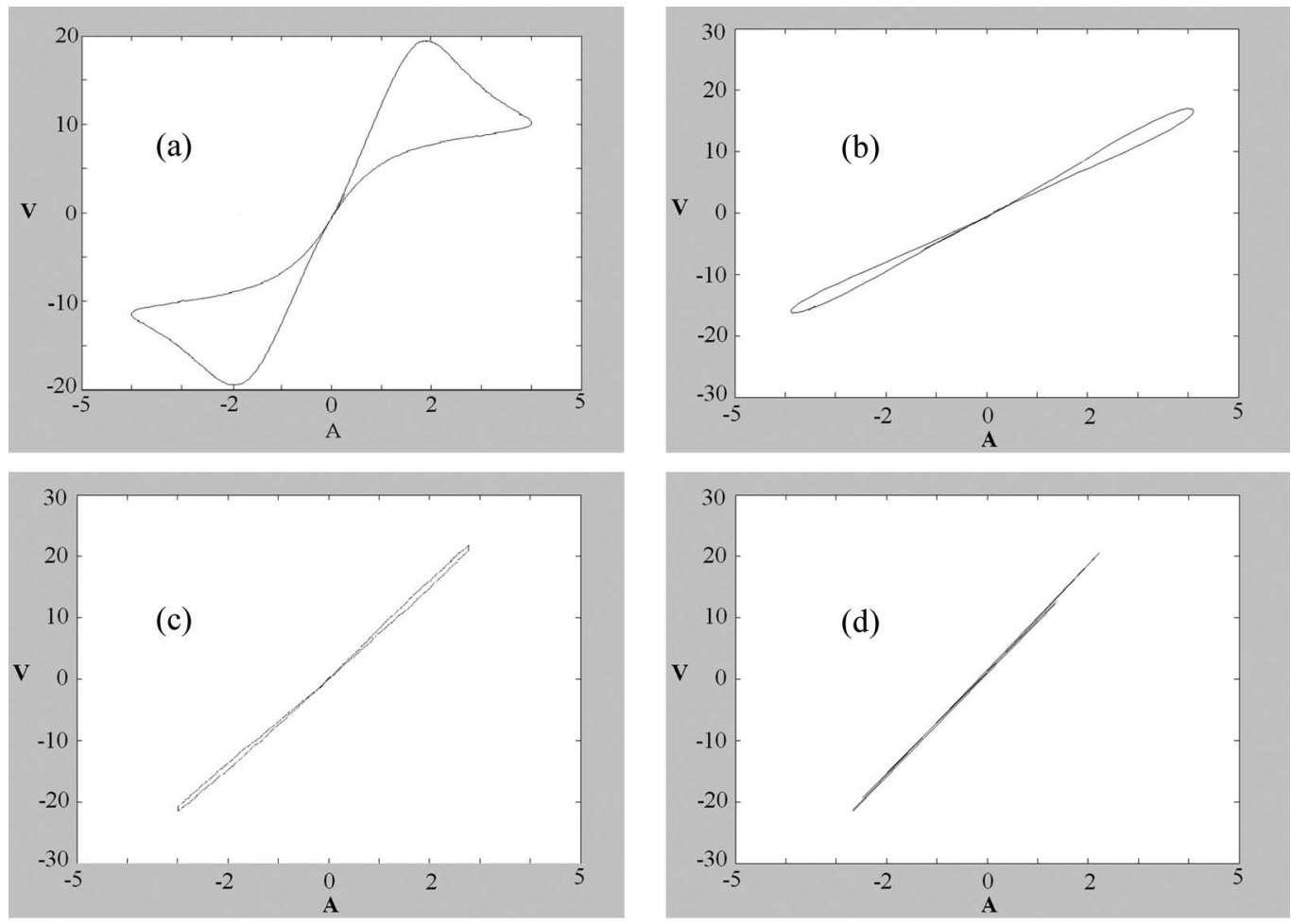

Fig. 7. Current (in amperes)-voltage (in volts) characteristics on the cathode of an HPS discharge, using a sinusoidal current (4 A): (a) $60 \mathrm{~Hz}$, (b) $1 \mathrm{kHz}$, (c) $10 \mathrm{kHz}$, and (d) $40 \mathrm{kHz}$.

TABLE II

RESUlt COMPARISONS OBTAINED FOR TUNGSTEN CATHODES IN HPS DischaRgES

\begin{tabular}{|c|c|c|c|c|c|c|}
\hline $\begin{array}{l}\text { Cathode } \\
\text { material }\end{array}$ & Gas & $\begin{array}{c}\text { Current } \\
{[\mathrm{A}]}\end{array}$ & Waveform & $\begin{array}{c}\text { Frequency } \\
\text { [Hz.] }\end{array}$ & $\begin{array}{c}\text { cathode } \\
\text { voltage drop } \\
\text { (peak) } \\
{[\mathrm{V}]}\end{array}$ & $\begin{array}{c}\text { cathode } \\
\text { voltage drop } \\
\text { (peak) } \\
\text { [V] }\end{array}$ \\
\hline Tungsten & sodium & 4.45 & sinusoidal & 60 & $17 \quad[2]$ & 16.4 ECM \\
\hline Tungsten & sodium & 4 & sinusoidal & 60 & 20 [5] & $19.5 \mathrm{ECM}$ \\
\hline
\end{tabular}

In addition, the cathode model here presented can be used to assess the influence of the frequency and waveform of the discharge current supply in the cathode operation. From the results shown in Fig. 7, we can conclude that, by increasing the frequency of the sinusoidal discharge current supply, the hysteresis at the electric cathode characteristics is reduced. This can be translated into a modulation decrease of the discharge impedance and better electronic control.

\section{ACKNOWLEDGMENT}

The authors would like to thank A. Cruz, F. Ramos, M. Duran, and M. Hidalgo for their technical assistance.

\section{REFERENCES}

[1] P. Flesch and M. Neiger, "Numerical simulation of dc high-pressure discharge lamps including electrodes," J. Phys. D, Appl. Phys., vol. 35, no. 14, pp. 1681-1694, Jul. 2002.

[2] J. J. de Groot and J. A. J. M. van Vliet, The High Pressure Sodium Lamp. Deventer, The Netherlands: MacMillan, 1986, pp. 258-275.

[3] P. Tielemans and F. Oostvogels, "Electrode temperature in high pressure gas discharge lamps," Philips J. Res., vol. 38, no. 4/5, pp. 214-223, 1983.
[4] J. C. Sherman, "Secondary electron emission by multiply charged ions and its magnitude in vacuum arcs," J. Phys. D, Appl. Phys., vol. 10, no. 3 , pp. 355-359, Feb. 1977.

[5] J. F. Waymouth, "Analysis of cathode-spot behavior in high-pressure discharge lamps," J. Light Vis. Environ., vol. 6, no. 2, pp. 53-64, 1982.

[6] M. Cristea and G. Zissis, "Thin barium layer formation and its influence on tungsten electrode arc attachment modes in HID lamps," J. Optoelectron. Adv. Mater., vol. 5, no. 2, pp. 511-520, Jun. 2003.

[7] P. Flesch, Light and Light Sources, High-Intensity Discharge Lamps. Berlin, Germany: Springer-Verlag, 2006, pp. 89-104.

[8] S. Coulombe and J. L. Meunier, "Thermo-field emission: A comparative study," J. Phys. D, Appl. Phys., vol. 30, no. 5, pp. 776-780, Mar. 1997.

[9] S. S. Mackeown, "The cathode drop in an electric arc," Phys. Rev., vol. 34, no. 4, pp. 611-614, Aug. 1929.

[10] S. Lichtenberg, D. Nandelstädt, L. Dabringhausen, M. Redwitz, J. Luhmann, and J. Mentel, "Observation of different modes of cathodic arc attachment to HID electrodes in a model lamp," J. Phys. D, Appl. Phys., vol. 35, no. 14, pp. 1648-1656, Jul. 2002.

[11] M. Cristea, I. Iova, C. P. Cristescu, I. M. Popescu, and J. J. Damelincourt, "Modelling nonlinear coupling between plasma, electrodes and walls for high-pressure Hg arc discharge lamps," Contrib. Plasma Phys., vol. 40, no. 5 , pp. $545-554$, Sep. 2000

[12] Math Works Inc., Simulink, Dynamic System Simulation for MATLAB, 2004. version 7, License Number: 259026.

[13] W. Elenbaas, The High Pressure Mercury Vapour Discharge. Amsterdam, The Netherlands: North Holland, 1951.

[14] J. F. Waymouth, Electric Discharge Lamps. Cambridge, MA: MIT Press, 1971. 


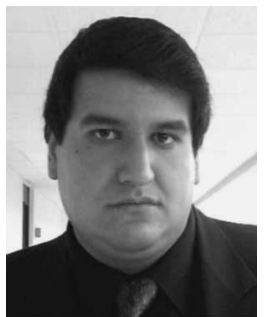

José Luis Tapia Fabela was born in México City, México, in 1977. He received the B.Sc. degree in electronics engineering from the Instituto Tecnológico de Toluca, Metepec, México, in 2000 and the M.Eng. degree in electronic engineering from the Instituto Tecnológico y de Estudios Superiores de Monterrey, Toluca, México, in 2002. He is currently working toward the Ph.D. degree at the Instituto Tecnológico de Toluca.

He has been involved in the area of high-intensitydischarge models and power electronics in the Thermal Plasma Applications Laboratory, Instituto Nacional de Investigaciones Nucleares, México DF, México.

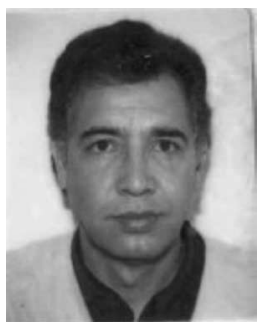

Joel Osbaldo Pacheco-Sotelo received the B.Sc. degree in industrial electronics and the M.Sc. degree in power electronics from Chihuahua Institute of Technology, Chihuahua, México, in 1974 and 1983, respectively, and the D.E.A. and Ph.D. degrees in electronics from the National Polytechnic Institute of Toulouse, Toulouse, France, in 1993.

Since 1974, he has been with the Instituto Nacional de Investigaciones Nucleares (ININ), México DF, México, where he has worked in several research and development projects that are related with thermal and nonthermal plasmas, electrical discharges, and pollution control. In 1987, he joined Instituto Tecnológico de Toluca, Metepec, México, where he is currently a Professor of power electronics. Since 1995, he has been responsible for the development and applications of the Thermal Plasma Applications Laboratory, ININ.

Dr. Pacheco-Sotelo has been a member of the National System of Researchers in México since 1989.

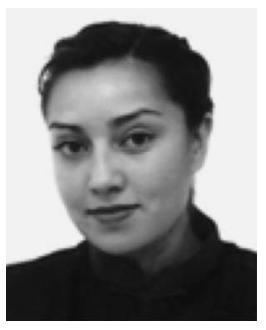

Marquidia Pacheco Pacheco was born in México City, México, on December 12, 1974. She received the B.S. degree in chemical engineering from the Instituto Tecnológico de Toluca, Metepec, México, in 1996 and the M.S. and Ph.D. degrees in physics and engineering of plasmas by studying the degradation of heavy oils with thermal plasma and the synthesis of carbon nanotubes by electric arc from Paul Sabatier University, Toulouse, France, in 1998 and 2003, respectively.

Since 2003, she has been with the Instituto Nacional de Investigaciones Nucleares, México DF, México, where she works in the application of new technologies for air-pollution control and new materials synthesis.

Dr. Pacheco is a member of the National System of Researchers in México.

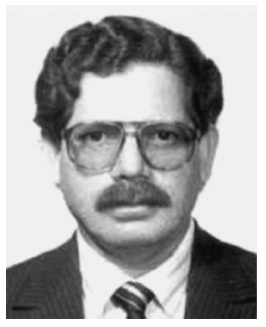

Jorge Samuel Benítez-Read received the B.Sc. degree in industrial engineering in electronics from Chihuahua Institute of Technology, Chihuahua, México, in 1979, the M.Eng. degree in electrical engineering from the University of Toronto, Toronto, ON, Canada, in 1985, and the Ph.D. degree in electrical engineering from the University of New Mexico, Albuquerque, in 1992.

From 1980 to 1981, he spent a year at the School of Industrial Engineers and the Empresarios Agrupados Nuclear Engineering Company, Madrid, Spain, in a specialization program in nuclear technology. Since 1981, he has been with Instituto Nacional de Investigaciones Nucleares, México DF, México, where he currently works in the area of automation and control of nuclear systems. Since 1987, he has also been lecturing graduate courses in control and electronics at the Instituto Tecnológico de Toluca, Metepec, México.

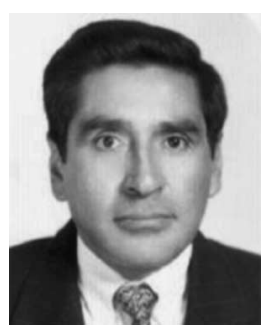

Régulo López-Callejas received the B.Sc. and M.Sc. degrees in electronics engineering from the National Polytechnic Institute of México, México City, México, in 1976 and 1986, respectively, and the $\mathrm{Ph} . \mathrm{D}$. degree in electronics engineering from the Instituto Tecnológico de Toluca, Metepec, México, in 2002.

Since 1979, he has been a Researcher in the Department of Plasma Physics, Instituto Nacional de Investigaciones Nucleares, México DF, México. His current scientific interests include plasma processing of materials, electronic instrumentation, and control systems.

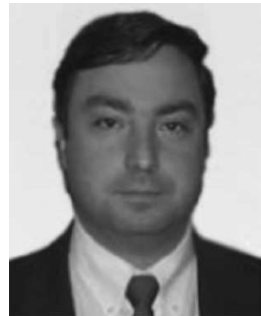

Georges Zissis (M'93-SM'06) was born in Athens, Greece, in 1964. He received the physics degree from the University of Crete, Crete, Greece, in 1986 and the M.S. and Ph.D. degrees in plasma science from Toulouse III University, Toulouse, France, in 1987 and 1990, respectively.

Since 1992, he has been with the Laboratoire Plasma et Conversion d'Energie, Université Paul Sabatier, Toulouse, France, as an Associate Professor until 2004 and, currently, as a Professor.

Dr. Zissis is currently the Chairman of the European network COST-529 "Efficient Lighting for the 21st Century." He is a member of the French National Council of Universities for Electrical Engineering. Since 2002, he has been the Secretary of the Production and Application of Light Committee of the IEEE Industry Applications Society.

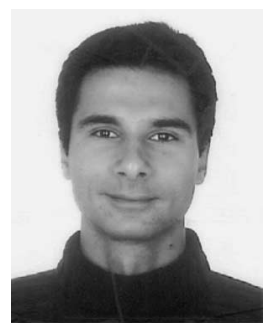

Sounil Bhosle (M'07) received the degree in plasma physics and the $\mathrm{Ph} . \mathrm{D}$. degree in plasma science from Toulouse III University, Toulouse, France, in 2001 and 2006, respectively.

$\mathrm{He}$ was with the Sources Intenses de Photons (High Intensity Photon Sources) Research Group, Laboratoire Plasma et Conversion d'Energie, Université Paul Sabatier, Toulouse, France, in 1997. This group, which is directed by Prof. G. Zissis, specializes in the experimental investigation and modeling of plasma discharge light sources. He specializes in the experimental aspect of the discharge-light-source investigation and is responsible of the dielectric barrier discharges (DBD) excilamps activity of the SIP research group.

Dr. Bhosle is the Secretary of the French Lighting Association from Midi Pyrenées. 